\title{
OPEN Study of nitrate levels in fruits and vegetables to assess the potential health risks in Bangladesh
}

\begin{abstract}
Rayhan Uddin ${ }^{1}$, Mostak Uddin Thakur², Mohammad Zia Uddin³ \& G. M. Rabiul Islam ${ }^{1 \bowtie}$
Nitrate is a chemical compound naturally present in fruits and vegetables. This study aims at assessing the nitrate levels and health risks arising from high consumption of fruits and vegetables in Bangladesh. Sixteen species of fruits and vegetables were examined for nitrates using HighPerformance Liquid Chromatography with Photo Diode Array (PDA) detector. Ward's hierarchical cluster analysis was carried out to identify the cluster of tested fruits and vegetables for the nitrate contents. A point estimate of the daily intake was applied to find the health risks that arise due to elevated levels of nitrate in fruits and vegetables. The results show that root and tuber vegetables accumulate significantly higher levels of nitrate in comparison to fruits and fruit vegetables $(P<0.05)$. In cluster analysis, the nitrate accumulation of fruits and vegetables show four clear clusters contributing to $29.54 \%, 7.17 \%, 4.42 \%$, and $58.57 \%$ of the total nitrate content in the entire sample. The risk assessment of the Estimated Daily Intake (EDI) and Health Risk Index (HRI) of almost all the tested samples was in the acceptable range, except for radish, thereby indicating the acceptance of risk due to nitrate intake in Bangladesh. As nitrate may have had risk factor for health, during cultivation and storing the product should be properly monitored.
\end{abstract}

Dietary inorganic nitrates have had a notoriously bad reputation for more than 50 years ${ }^{1}$. Currently, the concentration of nitrates in fruits and vegetables are exceeding the allowed limits worldwide ${ }^{2,3}$. This has led to strict regulations regarding the allowable levels of nitrate in our food based on the assumption that nitrate is overall harmful to our health. Concerns over nitrate intake originate from the fact that they are associated with the genesis of some forms of cancer and methemoglobinemia throughout the world ${ }^{4,5}$. They react with the secondary amines in the stomach and lead to the formation of nitrosamines (N-nitroso compounds), some of which are known to be carcinogenic, teratogenic, and mutagenic. This increases the risk of cancer to the stomach and esophagus $^{6-9}$. Some studies have evidence that a positive correlation exists between high nitrate consumption and gastric cancer in humans ${ }^{10,11}$. On the other hand, several plausible health benefits and preventive effects of nitrate have also been reported recently. A substantial number of studies in health and hypertensive subjects have now shown that nitrate has beneficial cardiovascular effects, including lowering of blood pressure ${ }^{12-17}$. Scientific evidence also suggests that having abundant vitamin $\mathrm{C}$ and polyphenol in fruits and vegetables facilitate in the nonenzymatic reduction of toxic nitrite to beneficial nitric oxide, thereby reducing the chances of nitrite reacting with secondary amines forming nitrosamines ${ }^{18,19}$. Therefore, it has been pointed out that the evidence for adverse effects of nitrate is inconsistent, and nitrate may actually be beneficial. Hence, the concepts of risk-benefit of exposure to dietary nitrate become a challenging/unresolved issue to the scientists.

Furthermore, Fruits and vegetables play an important role in alleviating micronutrient deficiencies and associated health repercussions, for example, lowering the risk of cancer, cardiovascular disease, and mortality ${ }^{20-24}$. Therefore, the Food and Agriculture Organization (FAO) and World Health Organization (WHO) recommend consuming at least $400 \mathrm{~g}$ /day of fruits and vegetables ${ }^{25}$. On the one hand, the per-capita consumption of fruits and vegetables in Bangladesh is substantially lower than the WHO norms, and there is an urgent need to encourage local value chains to deliver safe and affordable produce to the wider population ${ }^{26}$. On the other hand, nitrate pollution from chemical fertilizers, pesticide residue $(\mathrm{PR})$ overload in vegetables, and microbiological

${ }^{1}$ Department of Food Engineering and Tea Technology, Shahjalal University of Science and Technology, Sylhet 3114, Bangladesh. ${ }^{2}$ Department of Analytical Chemistry and Environmental Science, Training Institute for Chemical Industries, Narsingdi 1611, Bangladesh. ${ }^{3}$ Delta Pharma Limited, Pakundia Plant, Kishoreganj 2300, Bangladesh. ${ }^{\circledR}$ email: rabi-ttc@sust.edu 


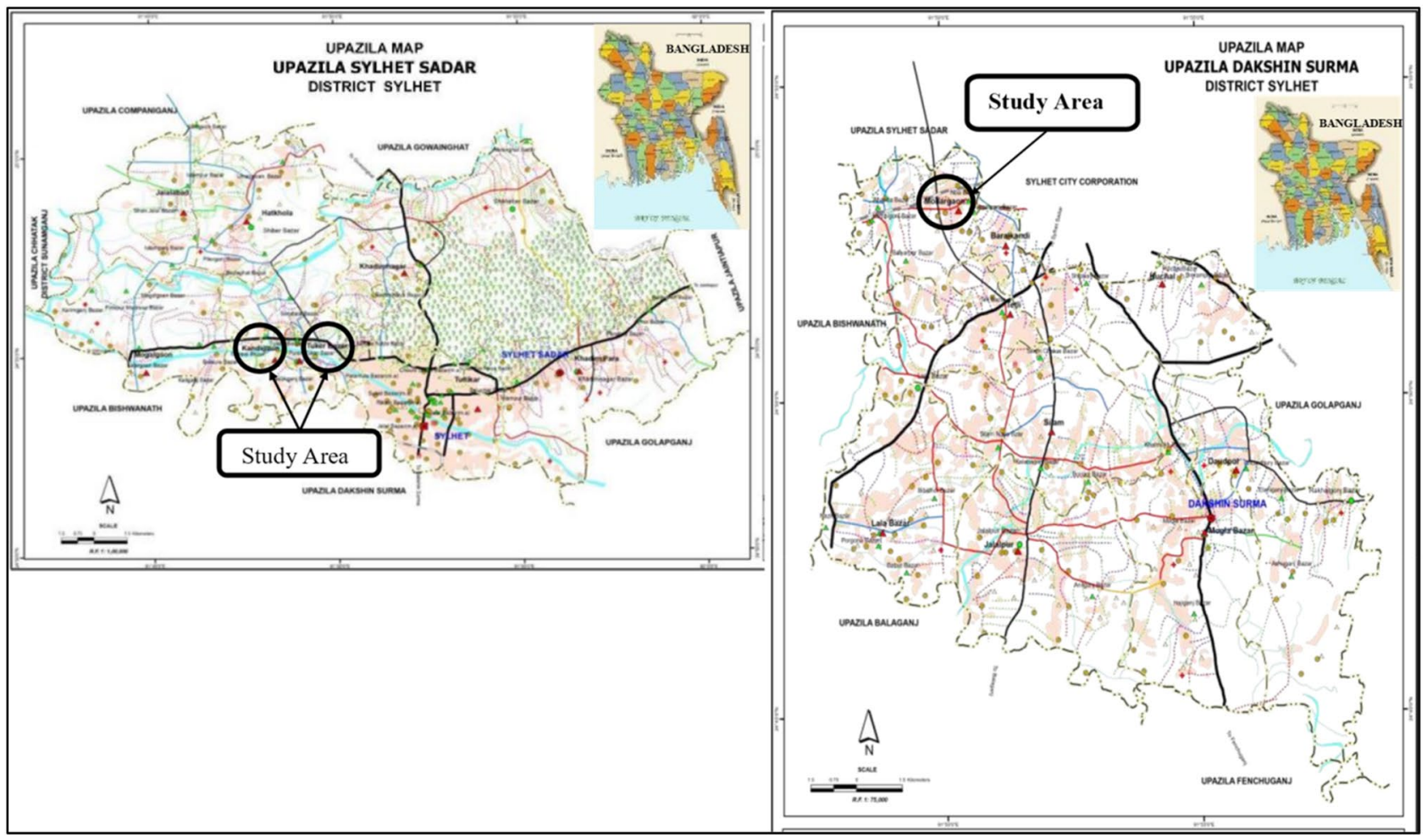

Figure 1. The study areas: Tuker Bazar and Kandergaon in Sylhet Sadar Upazila (left panel) and Mollargaon in Dakshin Surma Upazila (right panel) Source :(http://www.lged.gov.bd/ViewMap.aspx).

contamination along the value chain have emerged as alarming public health issues ${ }^{27}$. Some studies have shown that leafy vegetables and fruits contain higher levels of nitrate and contribute to about $85 \%$ of the dietary intake of nitrates in a number of societies ${ }^{20-22}$.The application of excessive nitrogen fertilizers to grow fruits and vegetables is one of the key factors for the accumulation of nitrates in fruits and vegetables ${ }^{28}$. Besides, the presence of nitrates in the produce also depends on a number of factors that can vary greatly from region to region such as biological properties of crop, lighting conditions, soil properties, humidity, frequency of planting in the field, vegetation period, season of harvest, processing time, geographical region and fertilization ${ }^{29-32}$.

The concept of hazard characterisation of micronutrients must consider that adverse effects may arise from intakes that are too low (deficiency) as well as too high (toxicity) ${ }^{33}$. The highest daily dose, at which no adverse effects are observed in the most susceptible animal species or model system during chronic exposure, is identified as the No Observable Adverse Effect Level (NOAEL). The NOAEL value is used as the basis for setting human safety standards for chemicals present in our diet, such as the TDI or the ADI. Being an agriculture-based country, Bangladesh grows a variety of fruits and vegetables throughout the year. However, it is true that in Bangladesh, there is a lack of information available for the levels of nitrate concentration in fruits and vegetables. Therefore, in this study, we aim to determine the concentration of nitrates in fruits and vegetables available in the local market as well as assess the health risk to humans upon consumption of the nitrate contaminated fruits and vegetables based on the Acceptable Daily Intake (ADI) and Health Risk Index (HRI), along with the established safety limits.

\section{Materials and methods}

Study area and sample collection. The preliminary phase of this study was conducted at Tuker Bazar, Kandigaon in Sylhet Sadar Upazila (left panel) and Mollargaon in Dakshin Surma Upazila (right panel) areas, which are the three major agriculturally productive regions in Sylhet division in Bangladesh (see Fig. 1). The longitudes selected were $24.9341^{\circ} \mathrm{N}$ and $91.8660^{\circ} \mathrm{E}$ for Tuker Bazar, $24.9111^{\circ} \mathrm{N}$ and $91.8075^{\circ} \mathrm{E}$ for Kandigaon, and $24.8753^{\circ} \mathrm{N}$ and $91.8270^{\circ} \mathrm{E}$ for Mollargaon.

The sites selected were based on crops grown, fertilizers used as well as opinions from local people and agricultural officers. The vegetables and fruits were selected based on two assumptions: (i) High consumption rate of fruits and vegetables among Bangladeshi people, and (ii) high nitrate content in fruits and vegetables grown in Bangladesh. All the samples were selected randomly at the time of their biological maturity during the growing season (May 2019 to December 2019). The samples were grouped into three viz., (i) root and tuber vegetables, (ii) fruit vegetables, and (iii) fruits. The samples were placed in a plastic bag and transferred to the laboratory after being labeled. The samples were kept overnight at a temperature below $4{ }^{\circ} \mathrm{C}$ until the analysis on the following day. The protocol of the study was approved by the Institutional Review Board of Shahjalal University of Science and Technology, Sylhet, Bangladesh No. AS/2019/2/33). 
Reagents and standards. Analytical grade potassium nitrate (Merck, Germany), hydrochloric acid (Sigma Aldrich), HPLC grade methanol and 1-Pentanesulfonic acid sodium salt were purchased from an online supplier. Deionized water was used for preparing all the solutions and also for sample extraction.

Sample preparation and extraction. The sample preparation and extraction were conducted according to the method developed by Hongsibsong et al. ${ }^{34}$. The non-edible parts were removed, and the samples were subjected to cutting and homogenization using a cutter and homogenizer, respectively. Then, the homogenized samples were immediately stored at $-20^{\circ} \mathrm{C}$ before the analysis. $50 \mathrm{~mL}$ of deionized water was added to $2 \mathrm{~g}$ of the homogenized sample in a $100 \mathrm{~mL}$ volumetric flask. The flask was then moved to a boiling water bath for $20 \mathrm{~min}$ at $80{ }^{\circ} \mathrm{C}$, shaken up and laid on the table to cool down, and further diluted to a final volume of $100 \mathrm{~mL}$ with deionized water. The first filtrate of $3 \mathrm{~mL}$ was discarded, and the rest was stored for the determination of nitrate. All the samples were analyzed within $1 \mathrm{~h}$ of preparation and extraction.

Determination of nitrate. The nitrate in the present study was analyzed according to the method described by Hsu et al. ${ }^{35}$ with some modifications. High-Performance Liquid Chromatography (HPLC) (Shimadzu HPLC Prominence- $i$ LC-2030 LT) with Photo Diode Array (PDA) detector was used to detect the nitrate. The separation was performed on $\mathrm{C}_{18}$ column (ZORBAX Eclipse XDB- $\mathrm{C}_{18}, 80 \AA$, $250 \times 4.6 \mathrm{~mm}, 5 \mu \mathrm{m}$ (Agilent Technologies).

The buffer solution used for the analytical procedures was prepared by dissolving $1.74 \mathrm{~g}$ of 1-Pentanesulfonic acid sodium salt in $950 \mathrm{~mL}$ deionized water and then added into a $1000 \mathrm{~mL}$ beaker; deionized water was used to dilute the solution up to the mark. $\mathrm{KNO}_{3}(162.79 \mathrm{mg})$ was weighed in a $100 \mathrm{~mL}$ volumetric flask and then dissolved in deionized water. Subsequent serial dilutions were made to achieve standards used for preparing the calibration curve of nitrate. The calibration curve was obtained by injecting five different concentrations of standard nitrate solutions of 100, 200,300, 400, and 500 ppm and plotting peak area against the concentration (ppm). The curve showed a high degree of linearity, where the slope appears at 13,690.2 with an average correlation coefficient, $\mathrm{R}^{2}=0.9962$. The Relative Standard Deviation (RSD) for peak areas was below $1 \%$. Therefore, we used the calibration curve to calculate the concentration of nitrate in selected fruits and vegetable samples and finally reported the values as $\mathrm{mg} \mathrm{kg}^{-1}$.

The mobile phase solution consisting of methanol (30\%) and buffer (70\%) was allowed to pass through the HPLC column until a stable baseline signal was equilibrated. The $\mathrm{pH}$ of the mobile phase was adjusted to 2.8 with $2 \mathrm{M}$ hydrochloric acid solution. The injection volume was $10 \mu \mathrm{L}$ with the flow rate set at $1 \mathrm{~mL} / \mathrm{min}$ and wavelength set at $225 \mathrm{~nm}$. The column oven temperature was $40{ }^{\circ} \mathrm{C}$, and the run time was $10 \mathrm{~min}$. As soon as the injections of the standard solution gave reproducible retention times and peak areas, each sample solution was injected for analysis. The peaks of the sample were identified by comparison with the respectable peaks of the standards.

Health risk estimation. The nitrate that enters into the body through fruits and vegetables becomes a substance of concern if it exceeds its Acceptable Daily Intake (ADI) limit or toxicity level, which may then lead to death ${ }^{36}$. The ADI for dietary nitrates is $3.7 \mathrm{mg} / \mathrm{kg}$ body weight according to the regulations of Joint Expert Committee of Food and Agriculture (JECFA) and the European Commission's Scientific Committee on Food $(\mathrm{SCF})^{37-39}$.

The daily intake of nitrate was calculated to estimate the average daily nitrate accumulation in a person of specific bodyweight and also to estimate the relative bioavailability of nitrate. The Estimated Daily Intake (EDI) does not take into account the possible metabolic excretion of the nitrate and considers only the possible ingestion rate. The EDI was calculated based on the following equation

EDI

$=\frac{\text { Average daily consumption of fruits and vegetables } \times \text { concentration of nitrate in fruits and vegetables }(\mathrm{mg} / \mathrm{kg})}{\text { Body weight }}$

$$
\text { Body weight }
$$

In Eq. (1) the average (per capita) consumption of vegetables and fruits was considered as 232 and $35.5 \mathrm{~g}$, respectively, as per the recent Household Income and Expenditure Survey ${ }^{26}$. We also calculated the EDI and HRI if a person consumed $400 \mathrm{~g}$ of fruits and vegetables as per the WHO and FAO guidelines ${ }^{40}$. In both cases, the body weight of $60 \mathrm{~kg}$ was taken for adults and $27 \mathrm{~kg}$ for children ${ }^{41}$. The calculated EDI was then compared with the ADI for the assessment of health hazards associated with the consumption of nitrate-containing fruits and vegetables.

Health Risk Index (HRI). An HRI $>1$ for any nitrate in food products means that the consumer population is at a potential health risk. The value of the Health Risk Index (HRI) depends on the EDI value of the food products and the oral Reference Dose (RfD). The oral RfD is the numerical estimate of the daily oral exposure of nitrate to humans that is not likely to cause harmful effects during the lifetime, including sensitive subgroups such as children ${ }^{42}$. The HRI for nitrate exposure due to consumption was calculated using the Eq. (2) reported by previous investigations ${ }^{43,44}$

$$
\mathrm{HRI}=\frac{E D I}{R f d}
$$




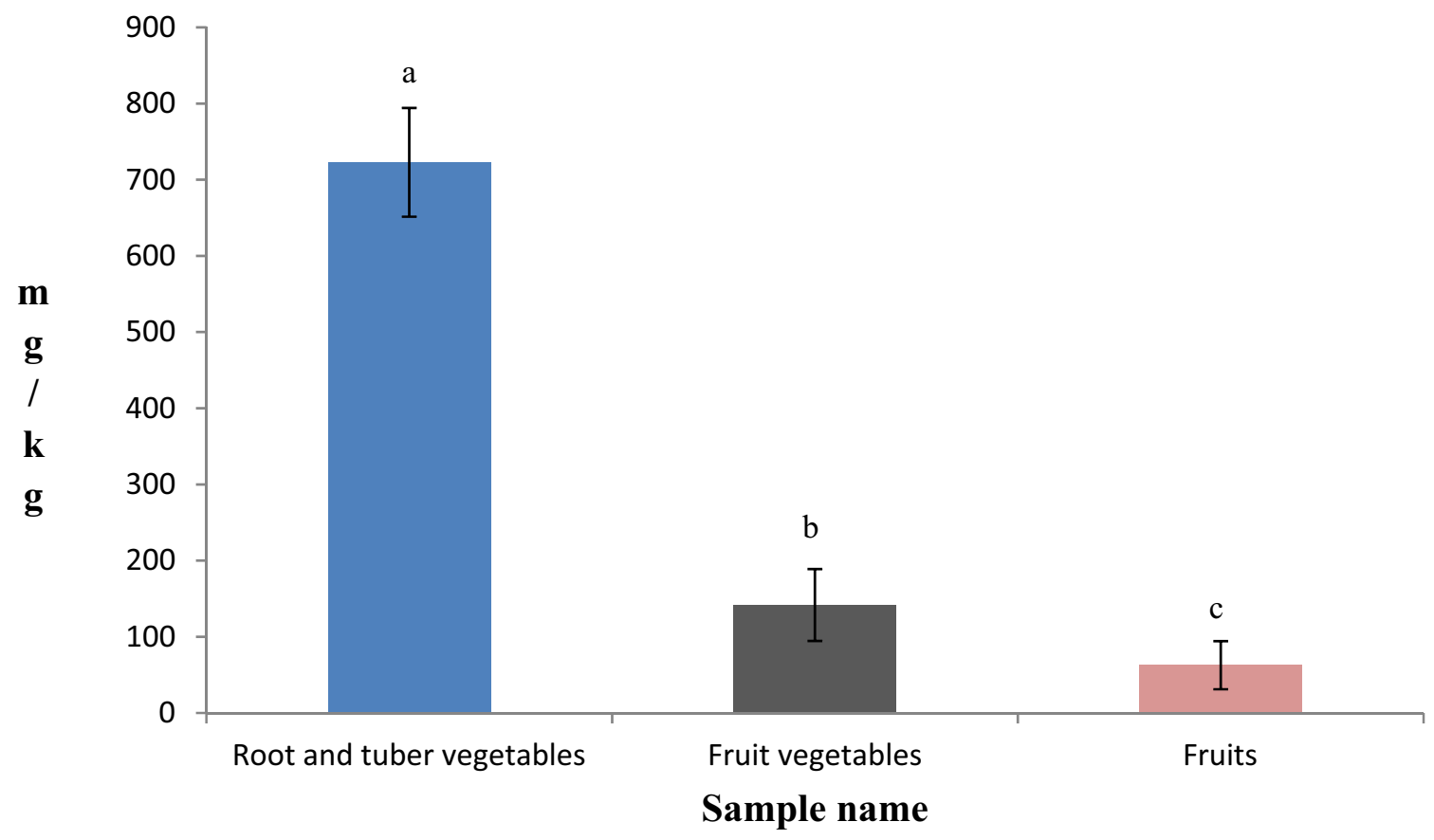

Figure 2. Nitrate levels in different tested root and tuber vegetables, fruit vegetables, and fruit samples. Error bars represent standard deviation. Columns that have the same letter are not significantly different at $\mathrm{P}$-value $=0.05$.

where EDI is for Estimated Daily Intake ( $\mathrm{mg} / \mathrm{kg}$ body weight/day), and Rfd is the reference dose ( $\mathrm{mg} / \mathrm{kg}$ body weight/day). The oral Rfd of the nitrate nitrogen is $1.6 \mathrm{mg} / \mathrm{kg}$ body weight/day, which is equivalent to $7.09 \mathrm{mg} / \mathrm{kg}$ body weight/day of nitrate according to the United States Environmental Protection Agency (USEPA) USEPA ${ }^{45}$.

Statistical analysis. All experiments were carried out in three replicates. The Shapiro-Wilk test is applied to determine the normal distribution of nitrate and EDI values. Since the data were not normally distributed, the Kruskal-Wallis test was performed to analyze the relative nitrate content of different food groups. The MannWhitney $\mathrm{U}$ test with Bonferroni correction was applied for the comparison of each group. The analysis was performed using R software for windows version (version 4.0.2). The $P$ values of $<0.05$ were considered to indicate statistical significance. Ward's hierarchical cluster analysis was used to categorize the tested fruits and vegetables in terms of their nitrate content.

\section{Results}

Nitrate in fruits and vegetables. Fruits and vegetables are recognized to provide a significant portion of nitrates in the nutritional regime. The samples analyzed in this present study were categorized and presented with their respective nitrate content in the previously mentioned groups of three.

Nitrates were detected in all the tested fruits and vegetables, and the results show that there is a significant difference in nitrate concentration among the root and tuber vegetables, fruit vegetables, and fruits $(\mathrm{p}<0.05)$. The nitrate content in root and tuber vegetables $(722.80 \mathrm{mg} / \mathrm{kg})$ was found to be significantly higher than that of fruit vegetables $(141.75 \mathrm{mg} / \mathrm{kg}$ ) (Fig. 2). In addition, lower nitrate content was observed in the fruit samples $(62.74 \mathrm{mg} / \mathrm{kg})$ when compared to the vegetables.

As presented in Table 1, among the root and tuber vegetables, the highest mean concentration of nitrate was determined in radish $(2501.24 \mathrm{mg} / \mathrm{kg})$ followed by potato $(307.19 \mathrm{mg} / \mathrm{kg})$ and carrot $(36.80 \mathrm{mg} / \mathrm{kg})$. In the case of fruit vegetables, brinjal scored the highest nitrate content followed by cauliflower and cucumber ( $>200 \mathrm{mg} /$ $\mathrm{kg}$ ). The nitrate concentration in lady finger and multitude appears within a magnitude of $100 \sim 150 \mathrm{mg} / \mathrm{kg}$. The nitrate concentration among other fruit vegetables appears below $100 \mathrm{mg} / \mathrm{kg}$. In the case of fruits, it was observed that the mean nitrate concentration of banana scored the highest $(200 \mathrm{mg} / \mathrm{kg})$, whereas other three fruits viz., apple, grape, and orange scored below $20 \mathrm{mg} / \mathrm{kg}$.

The cluster results of nitrate accumulation in fruits and vegetables are presented in Fig. 3 . As seen from this figure, the tested fruits and vegetables are categorized into four clear clusters. The first cluster includes brinjal, cauliflower, potato, cucumber, and banana. The second cluster includes fruit vegetables like lady finger and beans. The pumpkin, grape, apple, orange, tomato, carrot, and bitter guard comprise the third cluster, whereas the fourth cluster includes only radish. The first, second, third, and fourth groups are responsible for $29.54 \%$, $7.17 \%, 4.42 \%$, and $58.57 \%$ of the total nitrate content, respectively. 


\begin{tabular}{|c|c|}
\hline Fruits and vegetables & Nitrate \pm S.D. $(\mathrm{mg} / \mathrm{kg})$ \\
\hline \multicolumn{2}{|c|}{ Root and tuber vegetables } \\
\hline Carrot & $36.80 \pm 3.06$ \\
\hline Potato & $307.19 \pm 47.23$ \\
\hline Radish & $2501.24 \pm 342.81$ \\
\hline \multicolumn{2}{|l|}{ Fruit vegetables } \\
\hline Tomato & $43.19 \pm 31.15$ \\
\hline Cucumber & $214.57 \pm 14.45$ \\
\hline Cauliflower & $259.58 \pm 7.81$ \\
\hline Brinjal & $284.26 \pm 7.98$ \\
\hline Bean & $71.08 \pm 5.09$ \\
\hline Bitter Guard & $46.52 \pm 3.38$ \\
\hline Lady finger & $124.48 \pm 6.26$ \\
\hline Pumpkin & $20.23 \pm 2.45$ \\
\hline Multitude & $110.43 \pm 9.73$ \\
\hline \multicolumn{2}{|l|}{ Fruits } \\
\hline Banana & $196.09 \pm 138.82$ \\
\hline Apple & $17.92 \pm 2.52$ \\
\hline Grape & $19.07 \pm 3.07$ \\
\hline Orange & $17.90 \pm 1.95$ \\
\hline
\end{tabular}

Table 1. Mean concentrations of nitrate in the tested fruits and vegetables.

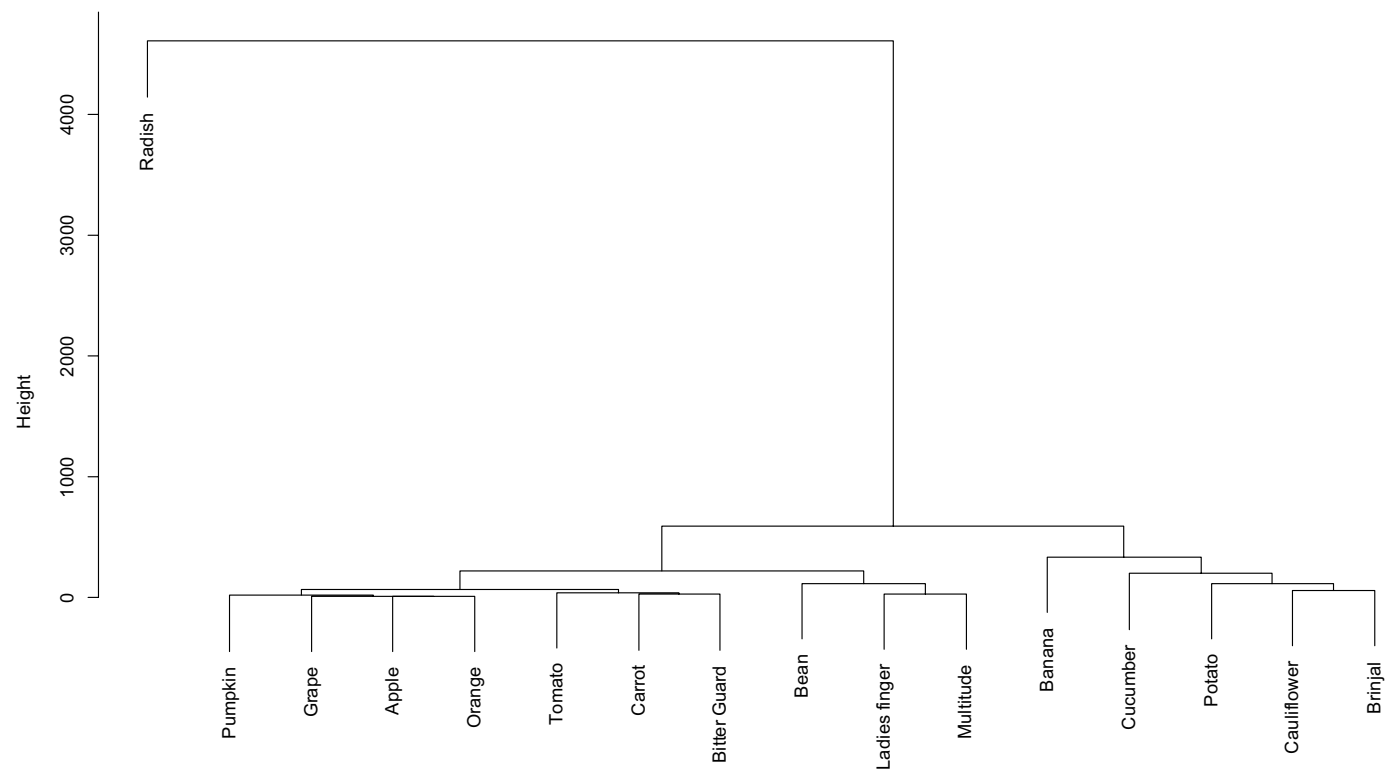

Figure 3. Dendrogram showing hierarchical clustering for nitrate content.

Health risk assessment. There is a direct correlation between the degree of toxicity of nitrate and daily intake. The health risk exposure of nitrate was calculated as Estimated Daily Intake (EDI) and Health Risk Index (HRI) in this study according to Eq. (1) and (2), and the outcomes were presented in Table 2.

Among the tested root and tuber vegetables, the highest EDI of nitrate appears in radish for adults followed by potato and carrot in both situations, i.e., as per current consumption and WHO recommendation. The Health Risk Index exceeds the accepted limit of 1 for adults and children only in the case of radish. The estimated daily intake of nitrate due to consumption of fruit vegetables like cucumber and cauliflower appears to be around $1 \mathrm{mg}$ $\mathrm{NO}_{3} / \mathrm{Kg}$ body weight for adults and $2 \mathrm{mg} \mathrm{NO}_{3} / \mathrm{Kg}$ body weight for children. The value varies between $3-4 \mathrm{mg}$ $\mathrm{NO}_{3} / \mathrm{Kg}$ body weight for children if the consumption is as per the WHO recommendation. For the other fruit vegetables, the current estimated daily intake is below $1 \mathrm{mg} \mathrm{NO} / \mathrm{Kg}$ body weight for adults. The EDI varies between $0.10-3 \mathrm{mg} \mathrm{NO}_{3} / \mathrm{Kg}$ body weight in the case of bananas for adults and children. For all the tested fruits and vegetables, the HRI is within its acceptable limit, i.e., less than 1. 


\begin{tabular}{|c|c|c|c|c|c|c|c|c|c|c|c|c|}
\hline \multirow[b]{3}{*}{ Fruit and vegetable samples } & \multicolumn{6}{|c|}{ According to current daily consumption } & \multicolumn{6}{|c|}{ According to WHO recommendation of consumption of $400 \mathrm{~g} / \mathrm{day}$} \\
\hline & \multicolumn{2}{|c|}{$\begin{array}{l}\mathrm{EDI}\left(\mathrm{mg} \mathrm{NO} \mathrm{N}_{3} \mathrm{Kg}\right. \\
\text { Body weight/day) }\end{array}$} & \multicolumn{2}{|l|}{$\% A D I$} & \multicolumn{2}{|l|}{ HRI } & \multicolumn{2}{|c|}{$\begin{array}{l}\text { EDI (mg NO }{ }_{3} / \mathrm{Kg} \\
\text { Body weight/day) }\end{array}$} & \multicolumn{2}{|l|}{$\% A D I$} & \multicolumn{2}{|l|}{ HRI } \\
\hline & Adult & Children & Adult & Children & Adult & Children & Adult & Children & Adult & Children & Adult & Children \\
\hline \multicolumn{13}{|l|}{ Root and tuber vegetables } \\
\hline Carrot & 0.14 & 0.31 & 3.78 & 8.38 & 0.02 & 0.04 & 0.25 & 0.55 & 6.76 & 14.86 & 0.04 & 0.08 \\
\hline Potato & 1.19 & 2.64 & 32.16 & 71.35 & 0.17 & 0.37 & 2.04 & 4.55 & 55.14 & - & 0.29 & 0.64 \\
\hline Radish & 9.61 & 21.49 & - & - & 1.36 & 3.03 & 16.67 & 37.06 & - & - & 2.35 & 5.23 \\
\hline \multicolumn{13}{|l|}{ Fruit vegetables } \\
\hline Tomato & 0.17 & 0.37 & 4.59 & 10 & 0.02 & 0.05 & 0.29 & 0.64 & 7.84 & 17.29 & 0.04 & 0.09 \\
\hline Cucumber & 0.83 & 1.84 & 22.43 & 49.73 & 0.12 & 0.26 & 1.43 & 3.18 & 38.65 & 85.94 & 0.20 & 0.45 \\
\hline Cauliflower & 1.00 & 2.23 & 27.03 & 60.27 & 0.14 & 0.31 & 1.73 & 3.85 & 46.76 & - & 0.24 & 0.54 \\
\hline Brinjal & 1.10 & 2.44 & 29.73 & 65.95 & 0.16 & 0.34 & 1.90 & 4.21 & 51.35 & - & 0.27 & 0.59 \\
\hline Bean & 0.27 & 0.61 & 7.30 & 16.49 & 0.04 & 0.09 & 0.47 & 1.05 & 12.70 & 28.38 & 0.07 & 0.15 \\
\hline Bitter Guard & 0.18 & 0.40 & 4.86 & 10.81 & 0.03 & 0.06 & 0.31 & 0.69 & 8.38 & 18.65 & 0.04 & 0.10 \\
\hline Lady finger & 0.48 & 1.07 & 12.97 & 28.92 & 0.07 & 0.15 & 0.83 & 1.84 & 22.43 & 49.73 & 0.12 & 0.26 \\
\hline Pumpkin & 0.08 & 0.17 & 2.16 & 4.59 & 0.01 & 0.02 & 0.13 & 0.30 & 3.51 & 8.11 & 0.02 & 0.04 \\
\hline Multitude & 0.43 & 0.95 & 11.62 & 25.68 & 0.06 & 0.13 & 0.74 & 1.64 & 20 & 44.32 & 0.10 & 0.23 \\
\hline \multicolumn{13}{|l|}{ Fruits } \\
\hline Banana & \begin{tabular}{|l|}
0.12 \\
\end{tabular} & 0.26 & 3.24 & 7.03 & 0.02 & \begin{tabular}{|l|}
0.04 \\
\end{tabular} & 1.30 & 2.91 & 35.14 & 78.64 & 0.18 & 0.41 \\
\hline Apple & 0.01 & 0.02 & 0.27 & 0.54 & 0.001 & 0.002 & 0.12 & 0.27 & 3.24 & 7.30 & 0.02 & 0.04 \\
\hline Grape & 0.01 & 0.03 & 0.27 & 0.81 & 0.001 & 0.004 & 0.13 & 0.28 & 3.51 & 7.57 & 0.02 & 0.04 \\
\hline Orange & 0.01 & 0.02 & 0.27 & 0.54 & 0.001 & 0.002 & 0.12 & 0.27 & 3.24 & 7.30 & \begin{tabular}{|l|}
0.02 \\
\end{tabular} & 0.04 \\
\hline
\end{tabular}

Table 2. Estimated Daily Intake (EDI) and Health Risk Index (HRI) for the Fruits and vegetables in accordance with the current daily consumption and WHO/FAO recommendation for adult and children.

\section{Discussion}

The results show that the highest content of nitrate was found in the root and tuber vegetables, followed by fruit vegetables and fruits. The reason for fruits containing lower concentrations of nitrate might be the use of less fertilizers in fruit cultivation in Bangladesh. These results coincide with the findings of Bahadoran et al., study from Iran ${ }^{22}$; Susin, kmecl and Gregorcic's study from Slovenia ${ }^{46}$.

From this study, it is clear that the mean concentration values of nitrate $(\mathrm{mg} / \mathrm{kg})$ detected in fruits and vegetables of Bangladesh were lower than those reported in other studies ${ }^{22,47-52}$. The nitrate content of the brinjal, beans, ladies finger and bitter guard were similar to the findings of Taghipour et al. ${ }^{53}$ and Taneja et al. ${ }^{54}$. Bangladesh has a tropical monsoon climate, which is characterized by wide seasonal variations in rainfall, high temperatures along with long sunshine periods. As reported by Escobar-Gutierrez et al. ${ }^{55}$, lower levels of nitrate in fruits and vegetables were related to high temperatures and longer sunshine periods. This may explain the overall lower levels of nitrate obtained in the present study. In contrast, a high concentration of nitrates and high variability between the findings, which contribute to the high standard deviation in some vegetable and fruit samples may be due to the soil type, use of fertilizers, time of harvesting, groundwater nitrate pollutions and agricultural practices $^{56-58}$. However, further investigation is required in this regard.

It appears that the EDI values for potato, tomato, carrot, cucumber, cauliflower from our studies were higher in comparison to the results of Gruszecka-Kosowska and Baran $\left(0.84,0.04,0.03,0.16,0.03 \mathrm{mg} \mathrm{NO}_{3} / \mathrm{Kg}_{\text {body }}\right.$ weight, respectively) from Poland ${ }^{59}$. Mehri et al.$^{60}$ in a study from Iran, reported high EDI values for carrot ( $0.19 \mathrm{mg} \mathrm{NO} / \mathrm{Kg}$ body weight) and tomato $\left(0.17 \mathrm{mg} \mathrm{NO}_{3} / \mathrm{Kg}\right.$ body weight $)$, which are similar to our findings. However, the EDI values reported for the potato samples $(0.13 \mathrm{mg} \mathrm{NO} / \mathrm{Kg}$ body weight) were lower than the results obtained in our study ${ }^{60}$.

Using the standard value of $3.7 \mathrm{mg} / \mathrm{kg}$ body weight/day as the benchmark of ADI threshold (as per the guidelines of WHO ${ }^{37}$; and HRI $<1$ (as the benchmark of HRI threshold), it was found that radish exceeds the permissible limit for both adults and children, indicating risks from nitrates. Several previous studies viz. Gruszecka-Kosowska and Baran from Poland, Suh et al. from Korea and Sebaeia and Refai from Egypt have demonstrated that no tested entity exceeds the standard value of $\mathrm{ADI}^{59,61,62}$. The reason for radish exceeding the threshold value of ADI in our study might be due to the intensity of fertilization, high nitrate accumulation rates, or the use of nitrate contaminated water.

The estimated daily intake and health risk index for each fruit and vegetable was calculated based on a daily consumption rate of $400 \mathrm{~g}$. In connection to this, the maximum permissible limit of $3.7 \mathrm{mg} / \mathrm{kg}$ body weight/day $\mathrm{ADI}$ as per the guidelines of WHO was found to exceed in radish for adults and radish, potato, cauliflower, and brinjal for children; Whereas for HRI only the radish was found to exceed the permissible limit.

Hence, this study indicates the adverse effects of nitrate pollution in fruits and vegetables in Bangladesh is acceptable. However, the reason for getting comparatively lower EDI and HRI values might be due to lesser contamination of fruits and vegetables with nitrate as well as lower than the recommended intake of fruits and vegetables $(400 \mathrm{~g} / \text { person/day })^{63}$. 
It should be kept in mind that consumption of fruits and vegetables is not the only route (though prime source) for nitrate to enter our body, and a Health Risk Index of less than 1 cannot alone indicate a safe and healthy level of nitrate intake. Therefore, other probable sources of nitrate, such as drinking water and other foodstuffs should be studied to determine the health risks of nitrate.

Limitations of the study. We have studied nitrate level in a few popular F\&V (fruits and vegetables) samples, which were available during our study time frame. This small-scale analysis does not represent the complete scenario of nitrate content in F\&V in Bangladesh. Therefore, more investigations need to be conducted on a large scale with a larger sample size to get the overall idea about the levels of nitrate available in fruits and vegetables in Bangladesh.

\section{Conclusion}

The prime concern for nitrate-rich diet is the endogenous formation of carcinogenic nitrosamines. Vegetables and fruits are considered the first contributors to dietary nitrate. This study clearly demonstrates that the average nitrate concentration in almost all samples was comparatively lower than that of the standard level. However, we must keep in mind that prolonged and inefficient storage, along with excessive use of chemical fertilizers and nitrate polluted water, contributes to elevated levels of nitrate in fruits and vegetables. Excluding radish, the HRI values of nitrate for other samples were $<1$, which indicates that health risks associated with nitrate exposure were not significant.

Therefore, the intake of nitrate through fruits and vegetables could be considered safe for the consumers. This is the very first study carried out to quantify the nitrate levels and assess the associated health risks in Bangladesh which will provide useful data to industry and health professionals.

Received: 8 September 2020; Accepted: 8 February 2021

Published online: 25 February 2021

\section{References}

1. Lundberg, J. O., Carlström, M. \& Weitzberg, E. Metabolic effects of dietary nitrate in health and disease. Cell Metab. 28, 9-22 (2018).

2. Petersen, A. \& Stoltze, S. Nitrate and nitrite in vegetables on the Danish market: content and intake. Food Addit. Contam. 16, 291-299 (1999).

3. Hord, N. G., Tang, Y. \& Bryan, N. S. Food sources of nitrates and nitrites: the physiologic context for potential health benefits. Am. J. Clin. Nutr. 90, 1-10 (2009).

4. Vickers, N. J. Animal communication: when i'm calling you, will you answer too?. Curr. Biol. 27, R713-R715 (2017).

5. Quijano, L. et al. Risk assessment and monitoring programme of nitrates through vegetables in the Region of Valencia (Spain). Food Chem. Toxicol. 100, 42-49 (2017).

6. Roohparvar, R., Shamspur, T., Mostafavi, A. \& Bagheri, H. Indirect ultra-trace determination of nitrate and nitrite in food samples by in-syringe liquid microextraction and electrothermal atomic absorption spectrometry. Microchem. J. 142, 135-139 (2018).

7. Cross, A. J. et al. Meat consumption and risk of esophageal and gastric cancer in a large prospective study. Am. J. Gastroenterol. 106, 432 (2011).

8. Loh, Y. H. et al. N-nitroso compounds and cancer incidence: the European Prospective Investigation into Cancer and Nutrition (EPIC)-Norfolk Study. Am. J. Clin. Nutr. 93, 1053-1061 (2011).

9. Ozdestan, O. \& Uren, A. Development of a cost-effective method for nitrate and nitrite determination in leafy plants and nitrate and nitrite contents of some green leafy vegetables grown in the Aegean region of Turkey. J. Agric. Food Chem. 58, 5235-5240 (2010).

10. Nowrouz, P., Taghipour, H., Dastgiri, S., Bafandeh, Y. \& Hashemimajd, K. Nitrate determination of vegetables in Varzeghan City, North-western Iran. Health Promot. Perspect. 2, 244 (2012).

11. Yang, C. Y., Cheng, M. F., Tsai, S. S. \& Hsieh, Y. L. Calcium, magnesium, and nitrate in drinking water and gastric cancer mortality. Jpn. J. Cancer Res. 89, 124-130 (1998).

12. Jonvik, K. L. et al. Nitrate-rich vegetables increase plasma nitrate and nitrite concentrations and lower blood pressure in healthy adults. J. Nutr. 146, 986-993 (2016).

13. Kerley, C. P., Dolan, E., James, P. E. \& Cormican, L. Dietary nitrate lowers ambulatory blood pressure in treated, uncontrolled hypertension: a 7-d, double-blind, randomised, placebo-controlled, cross-over trial. Br. J. Nutr. 119, 658-663 (2018).

14. Kapil, V., Khambata, R. S., Robertson, A., Caulfield, M. J. \& Ahluwalia, A. Dietary nitrate provides sustained blood pressure lowering in hypertensive patients: a randomized, phase 2, double-blind, placebo-controlled study. Hypertension 65, 320-327 (2015).

15. Jackson, J. K. et al. Vegetable nitrate intakes are associated with reduced self-reported cardiovascular-related complications within a representative sample of middle-aged Australian women, prospectively followed up for 15 years. Nutrients 11, 240 (2019).

16. Machha, A. \& Schechter, A. N. Inorganic nitrate: a major player in the cardiovascular health benefits of vegetables?. Nutr. Rev. 70, 367-372 (2012).

17. Velmurugan, S. et al. Dietary nitrate improves vascular function in patients with hypercholesterolemia: a randomized, doubleblind, placebo-controlled study. Am. J. Clin. Nutr. 103, 25-38 (2016).

18. Erkekoglu, P. \& Baydar, T. Evaluation of the protective effect of ascorbic acid on nitrite-and nitrosamine-induced cytotoxicity and genotoxicity in human hepatoma line. Toxicol. Mech. Methods 20, 45-52 (2010).

19. Rocha, B. S., Gago, B., Barbosa, R. M. \& Laranjinha, J. Dietary polyphenols generate nitric oxide from nitrite in the stomach and induce smooth muscle relaxation. Toxicology 265, 41-48 (2009).

20. Bondonno, C. P. et al. Vegetable-derived bioactive nitrate and cardiovascular health. Mol. Aspects Med. 61, 83-91 (2018).

21. Chetty, A. A., Prasad, S., Pinho, O. C. \& de Morais, C. M. Estimated dietary intake of nitrate and nitrite from meat consumed in Fiji. Food Chem. 278, 630-635 (2019).

22. Bahadoran, Z. et al. Nitrate and nitrite content of vegetables, fruits, grains, legumes, dairy products, meats and processed meats. J. Food Compos. Anal. 51, 93-105 (2016).

23. EFSA Panel on Food Additives and Nutrient Sources added to Food (ANS) et al. Re-evaluation of potassium nitrite (E 249) and sodium nitrite (E 250) as food additives. EFSA J. 15, e04786 (2017).

24. Aune, D. et al. Fruit and vegetable intake and the risk of cardiovascular disease, total cancer and all-cause mortality-a systematic review and dose-response meta-analysis of prospective studies. Int. J. Epidemiol. 46, 1029-1056 (2017). 
25. WHO, F. Fruit and Vegetables for Health: Report of a Joint FAO/WHO Workshop, 1-3 September 2004, Kobe, Japan. World Health Organization and Food and Agriculture Organization of the UN (2004).

26. HIES. Final Report on Household Income and Expenditure Survey-2016. Bangladesh Bureau of Statistics, Statistics Division, Ministry of Planning, Dhaka, Bangladesh (2019). https://drive.google.com/file/d/1TmUmC-0M3wC5IN6_tUxZUvTW2rmUxMc e/view.

27. Chan, T. Y. Vegetable-borne nitrate and nitrite and the risk of methaemoglobinaemia. Toxicol. Lett. 200, 107-108 (2011).

28. Fewtrell, L. Drinking-water nitrate, methemoglobinemia, and global burden of disease: a discussion. Environ. Health Perspect. 112, 1371-1374 (2004).

29. Parks, S. E., Irving, D. E. \& Milham, P. J. A critical evaluation of on-farm rapid tests for measuring nitrate in leafy vegetables. Sci. Hortic. 134, 1-6 (2012).

30. Reinik, M., Tamme, T. \& Roasto, M. Naturally Occurring Nitrates and Nitrites in Foods. In Bioactive Compounds in Foods (eds Gilbert, J. \& Şenyuv, H.) 227-254 (Wiley, Hoboken, 2008).

31. Rose, J. M., Bricker, S. B., Tedesco, M. A. \& Wikfors, G. H. A role for shellfish aquaculture in coastal nitrogen management. Environ. Sci. Technol. 48(5), 2519-2525 (2014).

32. Correia, M. et al. Contribution of different vegetable types to exogenous nitrate and nitrite exposure. Food Chem. 120, 960-966 (2010).

33. Dybing, E. et al. Hazard characterisation of chemicals in food and diet: dose response, mechanisms and extrapolation issues. Food Chem. Toxicol. 40, 237-282 (2002).

34. Hongsibsong, S., Polyiem, W., Narksen, W., Kerdnoi, T. \& Prapamontol, T. Determination of nitrate in the edible part of vegetables from markets around Chiang Mai city, northern Thailand by using high performance liquid chromatography. Asian J. Agric. Res. 8, 204-210 (2014).

35. Hsu, J., Arcot, J. \& Lee, N. A. Nitrate and nitrite quantification from cured meat and vegetables and their estimated dietary intake in Australians. Food Chem. 115, 334-339 (2009).

36. Du, S.-T., Zhang, Y.-S. \& Lin, X.-Y. Accumulation of nitrate in vegetables and its possible implications to human health. Agric. Sci. China 6, 1246-1255 (2007).

37. Hambridge, T. Nitrate and nitrite: intake assessment. WHO Food Addit. Ser. 50, 1053-1071 (2003).

38. Santamaria, P. Nitrate in vegetables: toxicity, content, intake and EC regulation. J. Sci. Food Agric. 86, 10-17 (2006).

39. SCF. Assessment of dietary intake of nitrates by the population in the European Union, as a consequence of the consumption of vegetable. In Reports on Tasks for Scientific Cooperation: Report of Experts Participating in Task 3.2.3, ed by European Commission, Brussels, p 34 . (1997).

40. 40FAO/WHO. Fruit and Vegetables for Health-Report of a Joint FAO/WHO Workshop. (Kobe, Japan, 2004).

41. Shaheen, N. et al. Health risk assessment of trace elements via dietary intake of 'non-piscine protein source'foodstuffs (meat, milk and egg) in Bangladesh. Environ. Sci. Pollut. Res. 23, 7794-7806 (2016).

42. Barnes, D. G. et al. Reference dose (RfD): description and use in health risk assessments. Regul. Toxicol. Pharmacol. 8, 471-486 (1988).

43. Abtahi, M. et al. The concentration of BTEX in the air of Tehran: a systematic review-meta analysis and risk assessment. Int. J. Environ. Res. Public Health 15, 1837 (2018).

44. Rahmani, J. et al. Contamination and prevalence of histamine in canned tuna from Iran: a systematic review, meta-analysis, and health risk assessment. J. Food Prot. 81, 2019-2027 (2018).

45. USEPA. Integrated Risk Information System (IRIS) (United States Environment Protection Agency, Washington, DC, 2013).

46. Sušin, J., Kmecl, V. \& Gregorčič, A. A survey of nitrate and nitrite content of fruit and vegetables grown in Slovenia during 1996-2002. Food Addit. Contam. 23, 385-390 (2006).

47. Temme, E. H. et al. Average daily nitrate and nitrite intake in the Belgian population older than 15 years. Food Addit. Contam.: Part A 28, 1193-1204 (2011)

48. De Martin, S. \& Restani, P. Determination of nitrates by a novel ion chromatographic method: occurrence in leafy vegetables (organic and conventional) and exposure assessment for Italian consumers. Food Addit. Contam. 20, 787-792 (2003).

49. Roila, R. et al. Contribution of vegetables and cured meat to dietary nitrate and nitrite intake in Italian population: safe level for cured meat and controversial role of vegetables. Ital. J. Food Saf. 7, 7692 (2018).

50. Stavroulakis, G. et al. Occurrence of nitrate in vegetables and dietary exposure assessment for the Cypriot adolescent consumers. Accred. Qual. Assur. 23, 115-122 (2018).

51. Colla, G., Kim, H.-J., Kyriacou, M. C. \& Rouphael, Y. Nitrate in fruits and vegetables. Sci. Hortic. 237, 221-238 (2018).

52. Feng, J.-F., Shi, Z., Wu, Y., Wu, H. \& Zhao, Y. Assessment of nitrate exposure in Beijing residents via consumption of vegetables. Chin. J. Food Hygiene 18, 514-516 (2006).

53. Taghipour, H. et al. Determination of nitrate concentration in consumed vegetables and estimation of that's dietary intake in Shabestar and Khameneh City, northwest of Iran: Azar Cohort study. Progr. Nutr. 21, 336-340 (2019).

54. Taneja, P., Labhasetwar, P., Nagarnaik, P. \& Ensink, J. H. The risk of cancer as a result of elevated levels of nitrate in drinking water and vegetables in Central India. J. Water Health 15, 602-614 (2017).

55. Escobar-Gutierrez, A., Burns, I., Lee, A. \& Edmondson, R. Screening lettuce cultivars for low nitrate content during summer and winter production. J. Hortic. Sci. Biotechnol. 77, 232-237 (2002).

56. Mahvi, A., Nouri, J., Babaei, A. \& Nabizadeh, R. Agricultural activities impact on groundwater nitrate pollution. Int. J. Environ. Sci. Technol. 2, 41-47 (2005).

57. Abdulrazak, S., Otie, D. \& Oniwapele, Y. Concentration of nitrate and nitrite in some selected cereals sourced within Kaduna state, Nigeria. Online J. Anim. Feed Res. 4, 37-41 (2014).

58. Amr, A. \& Hadidi, N. Effect of cultivar and harvest date on nitrate $\left(\mathrm{NO}_{3}\right)$ and nitrite $\left(\mathrm{NO}_{2}\right)$ content of selected vegetables grown under open field and greenhouse conditions in Jordan. J. Food Compos. Anal. 14, 59-67 (2001).

59. Gruszecka-Kosowska, A. \& Baran, A. Concentration and health risk assessment of nitrates in vegetables from conventional and organic farming. Hum. Ecol. Risk Assess.: Int. J. 23, 727-740 (2017).

60. Mehri, F., Heshmati, A., Moradi, M. \& Khaneghah, A. M. The concentration and health risk assessment of nitrate in vegetables and fruits samples of Iran. Toxin Rev. https://doi.org/10.1080/15569543.2019.1673424 (2019).

61. Suh, J. et al. Risk assessment on nitrate and nitrite in vegetables available in Korean diet. J. Appl. Biol. Chem. 56, 205-211 (2013).

62. Sebaei, A. S. \& Refai, H. M. Hazard index: probabilistic risk exposure of nitrate and nitrite in Egyptian fruits and vegetables. Int. J. Environ. Anal. Chem. https://doi.org/10.1080/03067319.2019.1685666 (2019).

63. Organization, W. H. WHO European Action Plan for Food and Nutrition Policy 2007-2012 (WHO Regional Office for Europe, Copenhagen, 2008).

\section{Author contributions}

This work was carried out in collaboration among all authors. Authors R.U. and M.Z.U. basic laboratory work. R.U. and G.M.R.I. wrote the protocol and wrote the first draft of the manuscript. G.M.R.I. and M.U.T. designed the study, supervised the work, and assisted financial support and reviewing the manuscript draft. 


\section{Competing interests}

The authors declare no competing interests.

\section{Additional information}

Correspondence and requests for materials should be addressed to G.M.R.I.

Reprints and permissions information is available at www.nature.com/reprints.

Publisher's note Springer Nature remains neutral with regard to jurisdictional claims in published maps and institutional affiliations.

(c) (i) Open Access This article is licensed under a Creative Commons Attribution 4.0 International License, which permits use, sharing, adaptation, distribution and reproduction in any medium or format, as long as you give appropriate credit to the original author(s) and the source, provide a link to the Creative Commons licence, and indicate if changes were made. The images or other third party material in this article are included in the article's Creative Commons licence, unless indicated otherwise in a credit line to the material. If material is not included in the article's Creative Commons licence and your intended use is not permitted by statutory regulation or exceeds the permitted use, you will need to obtain permission directly from the copyright holder. To view a copy of this licence, visit http://creativecommons.org/licenses/by/4.0/.

(c) The Author(s) 2021 